\title{
DIVERSIDADE GENÉTICA EM PALMEIRAS ATRAVÉS DE ISOENZIMAS E RAPD
}

\author{
SAWAZAKI, H. E., ${ }^{1}$ BOVI, M. L. A., ${ }^{2}$ \\ SODEK, L. ${ }^{3}$ e COLOMBO, C. A. ${ }^{1}$ \\ ${ }^{1}$ Centro de Genética, Biologia Molecular e Fitoquímica (IAC), C.P. 28, CEP 13001-970, Campinas, SP \\ ${ }^{2}$ Centro de Fruticultura (IAC), C.P. 28, CEP 13001-970, Campinas, SP \\ ${ }^{3}$ Departamento de Fisiologia Vegetal, UNICAMP, C.P. 6109, CEP 13083-970, Campinas, SP \\ Correspondência para: Haiko Enok Sawazaki, Centro de Genética, Biologia Molecular e Fitoquímica (IAC), \\ C.P. 28, CEP 13001-970, Campinas, SP, e-mail: henok@cec.iac.br \\ Recebido em 07/01/98 - Aceito em 15/05/98 - Distribuído em 30/11/98
}

(Com 11 figuras)

\begin{abstract}
Genetic relationships of palms based on enzimatic and RAPD polymorphism

Genetic diversity of palms was studied by means of enzymatic polymorphism using polyacrilamide gel electrophoresis and a DNA polymorphism assay based on the amplification of random DNA segments, denominated RAPD. Species and ecotypes from genus Euterpe, Bactris, Elaeis and Syagrus were utilized. Palm leaf extracts were utilized for isozymes of malate dehydrogenase (MDH), leucine aminopeptidase (LAP), glutamate oxaloacetate transaminase (GOT), phosphoglucose isomerase (PGI), phosphoglucose mutase (PGM), acid phosphatase (ACP), peroxidase (PRX), esterase (EST), and the RAPD markers technique, using the A and B kits from Operon Technologies. Interespecific differences were observed, as well as distinctive patterns for palm hybrids.

Some bands were observed in addition to those cited in the literature where starch gel electrophoresis was used for enzymatic polymorphism.

The conclusions with regard to polymorphic patterns obtained using the RAPD technique confirmed those observed with isozymes, with the advantages of its greater efficiency and ability to process a large number of samples.
\end{abstract}

Key words: heart of palm, peach palm, variability, hybrids.

\section{RESUMO}

Estudou-se, mediante polimorfismo enzimático em gel de poliacrilamida e polimorfismo de DNA com base na amplificação de segmentos de DNA ao acaso, denominado RAPD, a variabilidade genética em algumas espécies e ecótipos de palmeiras dos gêneros Euterpe, Bactris, Elaeis e Syagrus. Os extratos de folhas de mudas dessas palmeiras foram analisados para as isoenzimas de malato desidrogenase $(\mathrm{MDH})$, leucinoaminopeptidase (LAP), glutamato oxaloacetato transaminase (GOT), fosfoglucose isomerase (PGI), fosfoglucose mutase (PGM), fosfatase ácida (ACP), peroxidase (PRX), esterase (EST) e para os marcadores RAPD, utilizando os "primers" dos kits A e B da Operon Technologies.

Verificou-se grande variabilidade genética interespecífica, comprovada pelos dendrogramas UPGMA, com reconhecimento de híbridos.

Foram observadas várias bandas além das referidas pela literatura em gel de amido. Os resultados dos marcadores RAPD comprovaram os das isoenzimas com maior eficácia, pois possibilitaram facilmente a análise de grande número de marcadores genéticos.

Palavras-chave: juçara, açaí, pupunha, dendê, híbridos, variabilidade. 


\section{INTRODUÇÃO}

O Brasil é o principal produtor e exportador de palmito em conserva. As palmeiras mais usadas na exploração do palmito pertencem ao gênero Euterpe, da família Palmae. São plantas perenes e de grande porte, sendo que duas espécies são mais comuns: E. edulis Mart. (juçara), palmeira de estirpe único, cujo hábitat natural é o Centro-Sul do Brasil e E. oleracea Mart (açaí), palmeira que se caracteriza pelo farto perfilhamento, ocorrendo naturalmente na região Norte do país (Bovi \& Cardoso, 1978). Dentre as palmeiras não convencionais para produção de palmito e passíveis de serem cultivadas para tanto, destaca-se a pupunheira, Bactris gasipaes. Trata-se de palmeira precoce e rústica, com ocorrência natural na zona equatorial das Américas, apresentando várias raças ou tipos de acordo com tamanho e coloração de seus frutos. Apresenta, além da característica de perfilhamento, um desenvolvimento vegetativo bastante superior às espécies do gênero Euterpe (Bovi \& Cardoso, 1978).

Os primeiros estudos envolvendo palmeiras para produção de palmito no Instituto Agronômico (IAC) iniciaram em 1972, através da coleta e caracterização de germoplasma de espécies do gênero Euterpe (Bovi, 1984; Bovi et al., 1988). Atualmente, o programa de melhoramento genético envolve a obtenção e avaliação de híbridos interespecíficos no gênero Euterpe, assim como avaliação e seleção dentro da espécie Bactris gasipaes (Bovi et al., 1990, 1991, 1993). Outros gêneros de interesse para a produção de palmito, como Syagrus, Elaeis, Maximiliana e Archontophoenix, também vêm sendo estudados. Como parte desse programa de melhoramento, a geração de informações básicas sobre a diversidade genética do material botânico é constantemente utilizada; seja para auxiliar na escolha daqueles ecótipos com maior potencial de gerar efeitos heteróticos, seja para determinação das relações de parentesco entre espécies e ecótipos diferentes, no sentido de prever o êxito em cruzamentos.

Os genótipos de palmeiras com maior potencial agronômico são normalmente reunidos em coleção, constituindo-se assim o Banco Ativo de Germoplasma (BAG). Trabalhos de caracterização dos BAGs de palmeiras vêm sendo realizados sob o aspecto botânico, genético e agronômico (Bovi et al., 1995a, 1995b). Outros tipos de marcadores desenvolvidos para estimar a divergência genética de plantas foram as isoenzimas (Tanksley \& Octon, 1983). Utilizando esta metodologia para identificação de cultivares de palmeiras, Torres \& Tisserat (1980) avaliaram sete genes especificando cinco sistemas enzimáticos, álcool desidrogenase (ADH), EST, GOT, PGI e PGM, de um tipo de dendê, enquanto Ghesquiére (1983) trabalhou com pólen de Elaeis guineensis utilizando os sistemas enzimáticos $\mathrm{MDH}$, isocitrato desidrogenase (IDH), glucose-6-fosfato desidrogenase (G6PDH), PGI, PGM e ACP. Em palmiteiro, Ballvé (1988) iniciou os estudos de isoenzimas, desenvolvendo um conjunto de metodologias de eletroforese em gel de amido, tendo analisado diversas introduções de $E$. edulis e E. oleracea e seus respectivos híbridos.

Por este trabalho foram analisadas as isoenzimas de PRX, EST, ACP, ADH, PGI, ME e GOT em tecidos de caule, palmito e pólen de plantas adultas, raiz de mudas e tecidos de folhas de plantas em diversas fases de desenvolvimento, verificando-se a possibilidade da utilização do polimorfismo enzimático na identificação de híbridos e caracterização da origem de plantas.

O desenvolvimento do princípio de reações de polimerização em cadeia (PCR - "Polymerase Chain Reaction") permitiu o aparecimento de novas metodologias de marcador molecular, como o RAPD (Random Amplified Polymorphic DNA), que identifica o polimorfismo baseado na amplificação de fragmentos de DNA com tamanhos diferentes. Os marcadores moleculares RAPD baseiam-se no fato de que os "primers" são curtos o suficiente para que as sequiências complementares arbitrárias de oligonucleotídeos encontrem seqüências complementares no genoma, de tal forma que pares de "primers" estejam localizados próximos e com os respectivos finais 3'direcionados uns para os outros.

Em palmeiras, Shah et al. (1994) revelaram a utilização dos RAPDs para estudos de diversidade genética de dendê (Elaeis guineensis). Como a caracterização molecular e bioquímica dos acessos facilita o manejo e o uso do germoplasma conservado, este trabalho tem o objetivo de caracterizar geneticamente, através de isoenzimas e RAPD, parte do germoplasma de palmeiras do IAC mantido na forma de BAG. 


\section{MATERIAIS E MÉTODOS}

A caracterização enzimática e molecular dos genótipos de palmeiras foi realizada a partir das primeiras folhas quase totalmente expandidas de plântulas com quatro a seis meses de idade, crescidas em casa de vegetação. Os seguintes gêne- ros foram estudados: Euterpe (juçara, açaí e híbridos) e Bactris (pupunhas com e sem espinhos). Dois outros gêneros, Syagrus (gariroba) e Elaeis (dendê), geneticamente mais distantes das principais palmeiras produtoras de palmito, foram incluídos nas análises. A Tabela 1 relaciona os genótipos deste estudo.

TABELA 1

Relação dos gêneros, espécies e ecótipos de palmeiras utilizadas para análise.

\begin{tabular}{|c|c|c|c|}
\hline Gênero & Espécie & Ecótipo & Procedência \\
\hline \multirow[t]{9}{*}{ Euterpe } & E.edulis & Juçara branco & Pariqueraçu/SP \\
\hline & E.oleracea & Açaí roxo 1 & Belém/PA \\
\hline & E.oleracea & Açaí roxo 2 & Pariqueraçu/SP \\
\hline & E.caatinga & Tadeu & Recife/PE \\
\hline & E.sp & Açaí espada & I. Cumbu/PA \\
\hline & E.sp & Açaí itajobi & Itajobi/MG \\
\hline & E.sp & Açaí danilo & Pancas/ES \\
\hline & E.oleracea $x$ E.edulis & Híbrido & Pariqueraçu/SP \\
\hline & E. spiritosantensis & Bahia & Itabuna, Itubera/BA \\
\hline \multirow[t]{9}{*}{ Bactris } & B.gasipaes & Com espinhos & Yurimaguas/Peru \\
\hline & B.gasipaes & Sem espinhos & Yurimaguas/Peru \\
\hline & B.gasipaes & Walter & Belém/PA \\
\hline & B.gasipaes & Benjamim & Benjamim Constant/AM \\
\hline & B.gasipaes & Branca & Iquitos/Peru \\
\hline & B.gasipaes & Ceplac 10 & Itabuna/BA \\
\hline & B.gasipaes & EEU c/ espinhos & Ubatuba/SP \\
\hline & B.gasipaes & EEU s/ espinhos & Ubatuba/SP \\
\hline & B.gasipaes & $\mathrm{T} 2 \mathrm{~S} 1$ & Mococa/SP \\
\hline Syagrus & S.oleracea & Gariroba comum & Votuporanga/SP \\
\hline Elaeis & E.guineensis & Dendê hermes & Una/Bahia \\
\hline
\end{tabular}

Para os estudos das isoenzimas de fosfoglucose isomerase (PGI), glutamato oxaloacetato transaminase (GOT), esterase (EST), leucinoaminopeptidase (LAP), fosfatase ácida (ACP), peroxidase (PRX) e fosfoglucose mutase (PGM), as folhas, uma vez coletadas, foram manuseadas sob condições de baixa temperatura, ao redor de $4{ }^{\circ} \mathrm{C}$. Os extratos, a eletroforese e os sistemas enzimáticos foram realizados de acordo com metodologia estabelecida por Sawazaki (1995). As bandas foram denominadas com letras do alfabeto, de acordo com a velocidade de migração das mesmas.

Para as análises RAPD, a extração do DNA genômico total foi obtida através do ajuste da metodologia de Murray \& Thompson (1980). As concentrações de DNA foram determinadas em minifluorímetro para DNA TKO 100 da HOEFER. As amplificações foram realizadas empregandose primers de sequiência aleatória dos kits A e B da Operon Technologies. O volume da reação foi de $25 \mu \mathrm{l}$, sendo o produto das amplificações visualizado em gel de agarose 1,2\%, documentadas com câmara Polaróide MP4+ da PHOTODYNE sob luz UV.

Para interpretação dos resultados, as bandas obtidas foram codificadas como presentes (1) e ausentes (0), sendo somente consideradas para análise aquelas com forte intensidade em duas 
amplificações repetidas. A classificação dos genótipos em função das suas similaridades genéticas foi obtida através de um dendrograma, calculado a partir do método UPGMA ("unweighted pairgroup method with aritmetic mean"). Para cálculo das similaridades genéticas, empregou-se a seguinte fórmula:

$\mathrm{S}_{\mathrm{xy}}=a / a+b+c$

em que $a$ corresponde à soma das bandas presentes nos indivíduos $x$ e $y ; b$ corresponde à soma das bandas presentes somente em $x$; e $c$, à soma das bandas presentes somente em $y$; (Jaccard, 1908). Os coeficientes cofonéticos que quantificam a existência dos agrupamentos obtidos, foram originados pela comparação da matriz de similaridade de distância com a da similaridade cofonética. Todos os cálculos estatísticos foram realizados através do programa NTSYS (Rolhf, 1993).

\section{RESULTADOS E DISCUSSÃO}

\section{Polimorfismo enzimático}

PGI - O zimograma representativo dos fenótipos correspondentes à isoenzima PGI (Fig. 1) mostra duas regiões, denominadas A e B, sendo que a menos anódica apresenta o fenótipo característico de três bandas de uma enzima dímera, codificada por um loco heterozigoto. Esta região apresentou além das bandas do padrão básico, outras secundárias migrando mais rápido, sombreando as primeiras. Este fenômeno foi também observado por Torres \& Tisserat (1980) em dendê. Segundo estes autores, estas bandas seriam provenientes de modificações pós-transcrição, devido às condições da eletroforese. Como algumas vezes observou-se um padrão característico de seis bandas no híbrido, as três bandas extras são, provavelmente, bandas fantasmas decorrentes de modificações pós-transcrição, como sugerido por Torres \& Tisserat (1980). Para esta região (A - Fig. 1), estes autores observaram o sistema de proteínas diméricas e dois alelos, $\mathrm{F}$ e $\mathrm{S}$, correspondentes ao loco denominado Pgi-1. Neste trabalho, foram observadas as três bandas e seis possíveis alelos. Esta região apresentou fenótipos diferentes para pupunha, dendê, gariroba, juçara e açaí e, se forem consideradas as seis eventuais bandas do híbrido, algumas vezes diferenciou o híbrido de Euterpe dos respectivos parentais (E. oleracea e E. edulis).
Na região B do loco Pgi-2, que segundo Torres \& Tisserat (1980) apresentou-se como variável, foram observadas bandas difusas, tendo as bandas do dendê (Elaeis guineensis) e das pupunhas (Bactris gasipaes) migração mais rápida, as das palmeiras do gênero Euterpe (E. edulis e E. oleracea) e seus respectivos híbridos, migração intermediária, e as da gariroba (Syagrus oleracea), migração mais tardia.

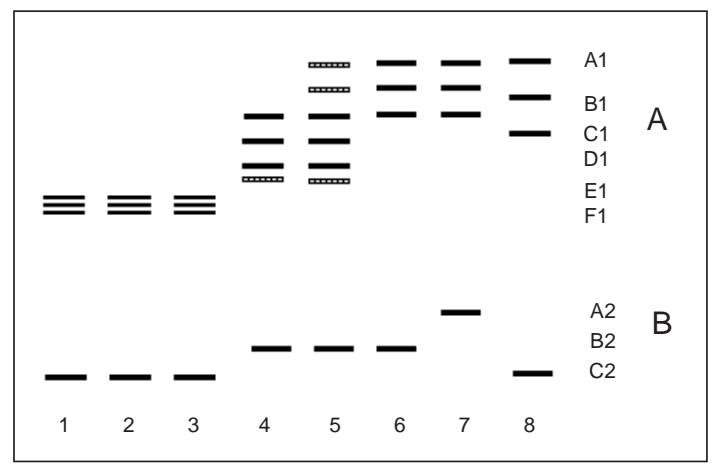

Fig 1 - Zimograma de PGI de palmeiras. 1 = walter = $2=3$ = yurimaguas com e sem espinho com bandas na região $\mathrm{A}$ : $\mathrm{E} 1, \mathrm{~F} 1$ e banda na região $\mathrm{B}$ : $\mathrm{C} 2 ; 4$ = açaí $\mathrm{B} 1$, D1 e B2; 5 = híbrido B1, D1 e B2; $6=$ juçara A1, B1 e $\mathrm{B} 2 ; 7$ = gariroba $\mathrm{A} 1, \mathrm{~B} 1$ e A2; 8 = dendê hermes $\mathrm{A} 1, \mathrm{C} 1$ e $\mathrm{C} 2$.

GOT - O zimograma correspondente às isoenzimas de GOT (Fig. 2) mostra a presença de bandas em duas regiões, sendo a sobreposição das mesmas devida ao fato das bandas correspondentes à primeira região dos ecótipos de dendê e gariroba apresentaram-se mais avançadas que nos demais genótipos. A região mais lenta (A Fig. 2) correspondeu àquela codificada pelo loco denominado Got-1 por Torres \& Tissrat (1980), que, estudando genótipos de dendê, observaram o sistema dimérico e dois alelos, F e S. Neste estudo, foram observadas nesta região a presença de uma a três bandas e seis possíveis alelos. A presença de uma banda correspondente ao genótipo homozigoto foi observada na gariroba e nas pupunhas, tendo o ecótipo Walter desta última apresentado três bandas. Os demais genótipos apresentaram três bandas, correspondentes ao heterozigoto, com fenótipos distintos para dendê, açaí, juçara e o respectivo híbrido. Algumas vezes foi observada a não-formação do híbrido heterozigoto no dendê, como mostrado no 
fenótipo número 9 da Fig. 2. Em dendês, Torres \& Tisserat (1980) observaram um ou dois alelos, denominados $\mathrm{F}$ e $\mathrm{S}$, na região correspondente ao Got-2, codificando uma ou duas bandas do sistema monomérico. Neste trabalho, encontrou-se apenas uma banda e três diferentes velocidades de migração, sendo a mais rápida para as palmeiras do gênero Euterpe, a intermediária para as pupunhas e a mais lenta para o dendê e a gariroba.

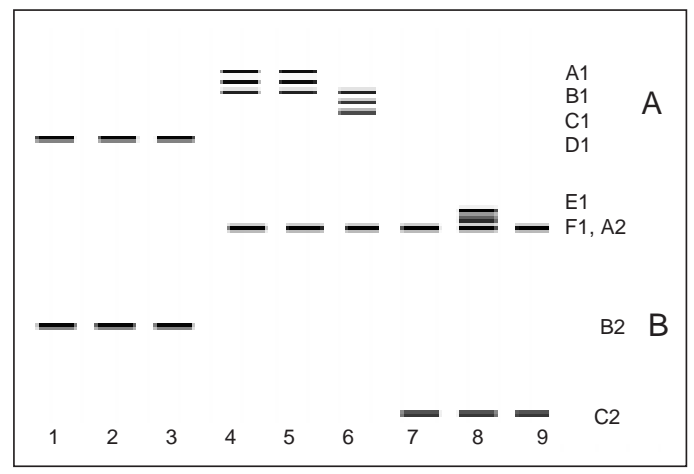

Fig. 2 - Zimograma de GOT de palmeiras. $1=$ walter $=2=$ 3 = yurimaguas com e sem espinho com banda na região $\mathrm{A}$ : D1 e banda na região $\mathrm{B}: \mathrm{B} 2 ; 4=$ açaí $=5=$ híbrido $=\mathrm{A} 1, \mathrm{~B} 1$ e A2; $6=$ juçara $\mathrm{B} 1, \mathrm{C} 1$ e A2; $7=$ gariroba $\mathrm{F} 1$ e $\mathrm{C} 2 ; 8=9=$ dendê hermes E1, F1 e C2 ou F1 e C2.

EST - O perfil das isoenzimas de EST (Fig. 3) mostra bandas em duas regiões. Na região próxima à origem (A - Fig. 3) encontramos uma ou duas bandas, resultado semelhante ao observado por Ballvé (1988). Bandas dos açaízeiros, juçara e do híbrido entre ambos (todos do gênero Euterpe) são observadas nesta região. As pupunhas não apresentaram bandas nesta região, configurando a hipótese do alelo nulo, ou suas bandas, mais avançadas, estariam deslocadas para a segunda região (B - Fig. 3). Considerando-se a hipótese do alelo nulo, o sistema poderia ser monomérico com duas aloenzimas, tendo açaí e o híbrido uma aloenzima mais retardada, e a juçara duas aloenzimas. Neste caso, as pupunhas teriam a ausência de fenótipo, ficando a juçara fenotipicamente diferenciada em relação ao híbrido e ao açaí. Se for considerado o deslocamento das bandas para a segunda região, o sistema poderia ser dimérico pela presença de três bandas nas pupunhas. Como, porém, a juçara tem apenas duas bandas, esta hipótese é menos provável. A segunda região apresentou várias bandas, provavelmente decorrentes da multiplicidade de ação desta enzima em vários substratos (Alfenas et al 1991; Weeden \& Wendel, 1989), configurando provável codificação por dois ou mais locos. As bandas menos anódicas desta região também diferenciaram açaí e o híbrido de juçara, pois esta última não apresentou estas bandas.



Fig. 3 - Zimograma de EST de palmeiras. 1 = walter; 2 = yurimaguas; 3 = açaí $=4$ = híbrido; $5=$ juçara.

LAP - Pelo zimograma dos fenótipos correspondentes às isoenzimas de LAP (Fig. 4) verifica-se que as pupunhas apresentaram duas bandas bem separadas, enquanto que nos demais estas bandas estão presentes numa só região. Esta configuração caracteriza o sistema como sendo monomérico, com um loco heterozigoto ou dois locos homozigotos. Considerando-se apenas um loco, os prováveis genótipos heterozigotos seriam codificados por sete alelos. No caso de se considerar dois locos homozigotos, um correspondendo ao fenótipo mais próximo da origem (A Fig. 4) e outro correspondente ao fenótipo mais avançado (B - Fig. 4), teríamos quatro alelos para a região A e três alelos para a região B. Os perfis obtidos diferenciaram as pupunhas, o dendê, a gariroba e as palmeiras do gênero Euterpe.

ACP - As isoenzimas de ACP (Fig. 5) apresentaram bandas em duas regiões. A região menos anódica (A - Fig. 5), apresentou o fenótipo de uma a três bandas, típico de enzima dimérica, enquanto que a região mais anódica (B - Fig. 5) apresentou apenas uma, o que caracterizaria a existência de dois locos. As palmeiras do gênero Euterpe apresentaram uma banda mais lenta na re- 
gião A, sendo que esta banda não esteve presente em todos ecótipos de pupunha. Nesta mesma região, a gariroba apresentou uma banda mais rápida, ausente nas demais. O dendê apresentou o fenótipo de três bandas, característico do genótipo heterozigoto. Foram observados três possíveis alelos. A região mais adiantada apresentou apenas uma banda, com duas velocidades de migração, sendo a mais retardada observada somente na gariroba e a mais avançada, nos demais.

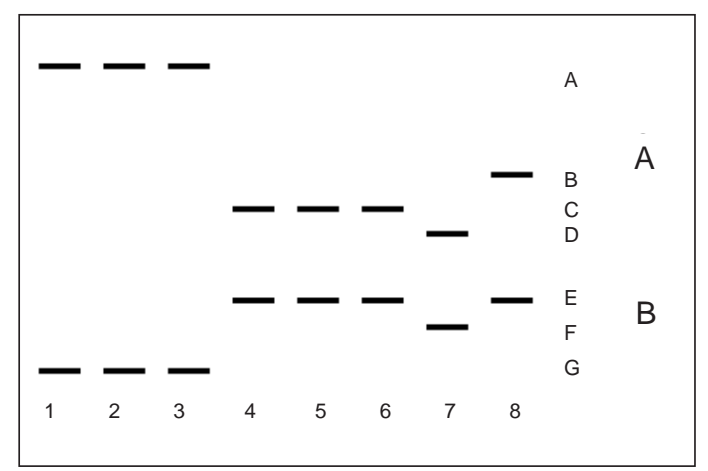

Fig. 4 - Zimograma de LAP de palmeiras. 1 = walter $=$ $2=3$ = yurimaguas com e sem espinho com bandas $\mathrm{A}$ e G; 4 = açaí $=5$ = híbrido $=6=$ juçara com bandas $\mathrm{C}$ e E; 7 = gariroba com bandas $\mathrm{D}$ e F; $10=$ dendê hermes com bandas B e E.

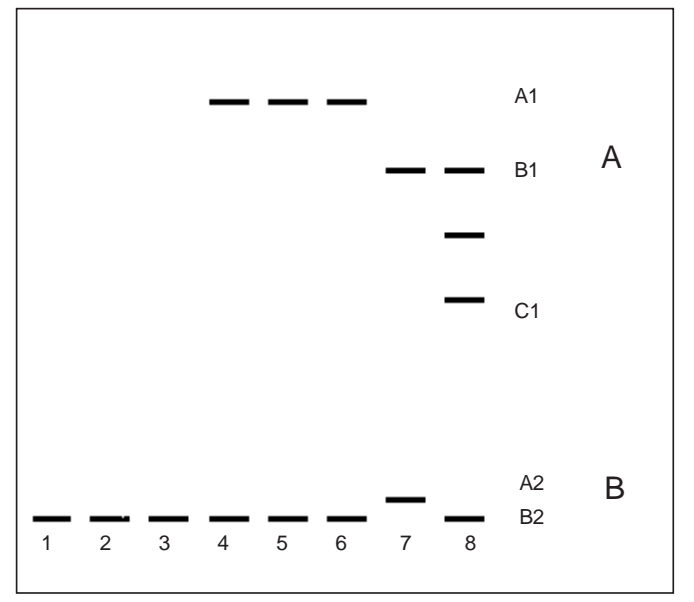

Fig. 5 - Zimograma de ACP de palmeiras. $1=2=3=$ walter, yurimaguas com e sem espinho com banda na região $\mathrm{B}$ : $\mathrm{B} 2 ; 4=$ açaí $=5=$ híbrido $=6=$ juçara $=\mathrm{A} 1$ e B2; 7 = gariroba B1 e A2; $8=$ dendê hermes B1, C1 e B2.

PRX - O zimograma dos fenótipos correspondentes às isoenzimas do sistema PRX (Fig. 6) mostra bandas em duas regiões distintas. Na região mais próxima da origem, palmeiras do gênero Euterpe apresentaram uma banda difusa. Entre as Euterpe, no ecótipo juçara houve aparecimento de três bandas, sendo que nos demais apenas uma banda foi observada, caracterizando assim a provável codificação por um loco. Na região mais avançada, foi observada uma banda muito difusa e variável nas pupunhas, assim como outra de fraca atividade na gariroba e no dendê. Este resultado confirma a hipótese de que os locos podem ser produtos de genes estruturalmente não relacionados, próprios de enzimas com múltiplos substratos, como é o caso da peroxidase (Alfenas, et al 1991). A multiplicidade de substratos possibilita a expressão de diferentes produtos, podendo assim explicar a fraca atividade observada na gariroba e no dendê hermes. As palmeiras do gênero Euterpe apresentaram um padrão de sete ou oito bandas na açaí, seis na juçara e sete ou oito no híbrido. Os ecótipos de açaí apresentaram bandas sempre menos anódicas que os de juçara, sendo o híbrido entre elas caracterizado por uma banda atrasada intermediária.

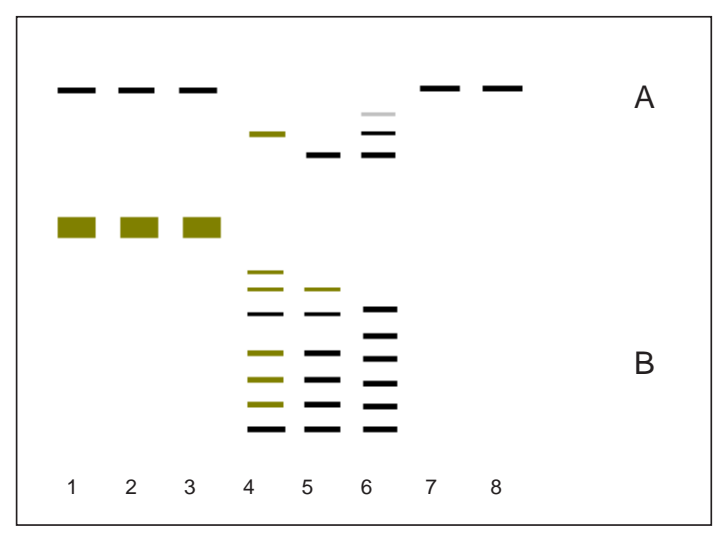

Fig. 6 - Zimograma de PRX de palmeiras. 1 = walter = $2=3$ = yurimaguas sem e com espinho; $4=$ açaí; $5=$ híbrido; 6 = juçara; $7=$ dendê hermes; $8=$ gariroba.

PGM - As isoenzimas de PGM (Fig. 7) apresentaram uma ou duas bandas em uma região, com seis diferentes velocidades de migração. Estes resultados são concordantes aos de Torres \& Tisserat (1980), que observaram os alelos F e S em dendê e que, segundo estes autores, corresponderia ao perfil de proteínas monoméricas. Nos ecótipos de dendê e nos de pupunhas, observouse o perfil de uma banda, embora diferentes, sendo que o ecótipo de pupunha walter apresentou 
um padrão de uma banda menos deslocada, podendo caracterizar uma outra aloenzima. As demais apresentaram duas bandas correspondentes ao genótipo heterozigoto, sendo observados fenótipos diferentes para os ecótipos gariroba, juçara, açaí e no híbrido destas duas últimas.

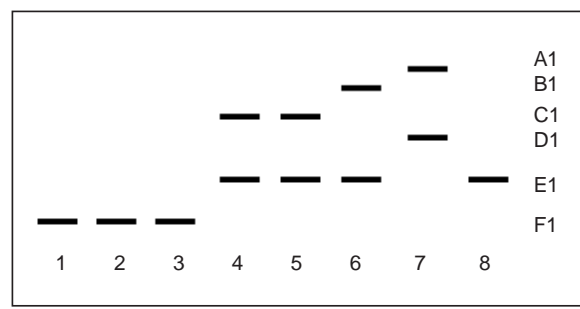

Fig. 7 - Zimograma de PGM de palmeiras. 1 = walter = $2=3$ = pupunhas sem e com espinho com as bandas F1; 4 = açaí $\mathrm{C} 1$ e $\mathrm{E} 1 ; 5$ = híbrido $\mathrm{C} 1$ e E1; 6 = juçara $\mathrm{B} 1$ e $\mathrm{E} 1 ; 7=$ dendê hermes A1 e D1; 8 = gariroba E1.

MDH - Pelas isoenzimas de MDH (Fig. 8) observou-se que ocorreu variabilidade entre pupunhas provenientes de sementes com tamanho e formato diferentes, pois embora de um mesmo lote, apresentaram ausência ou presença de uma banda.

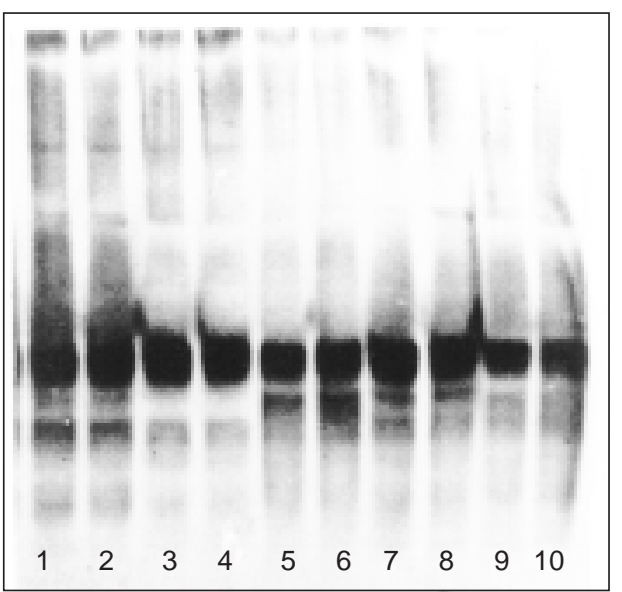

Fig. 8 - Zimograma de MDH de palmeiras. De 1 a 10 yurimaguas provenientes de sementes de formas e tamanhos diferentes: $1=2=$ sem espinho/pequena bicuda; $3=4=\mathrm{com}$ espinho/grande redonda; $5=6=$ sem espinho/grande redonda; $7=8=$ com espinho/grande bicuda; $9=10=$ sem espinho/ grande bicuda.

\section{Polimorfismo de marcadores RAPDs}

Dos 40 "primers" inicialmente testados, vinte e quatro foram selecionados em função da qualidade e repetição das bandas amplificadas. No total,

TABELA 2

Lista dos "primers" utilizados, número total e número de fragmentos polimórficos amplificados.

\begin{tabular}{|c|c|c|}
\hline Primers & $\begin{array}{c}\text { Total de } \\
\text { fragmentos }\end{array}$ & $\begin{array}{c}\text { Fragmentos } \\
\text { polimórficos }\end{array}$ \\
\hline OPA1 & 10 & 9 \\
\hline OPA2 & 8 & 8 \\
\hline OPA3 & 8 & 8 \\
\hline OPA4 & 11 & 11 \\
\hline OPA5 & 9 & 9 \\
\hline & & \\
\hline & & \\
\hline OPA8 & 8 & 12 \\
\hline OPA9 & 12 & 10 \\
\hline OPA10 & 10 & 11 \\
\hline OPA11 & 11 & \\
\hline & & \\
\hline & & \\
\hline & & \\
\hline & & \\
\hline
\end{tabular}

\begin{tabular}{|c|c|c|}
\hline Primers & $\begin{array}{c}\text { Total de } \\
\text { fragmentos }\end{array}$ & $\begin{array}{c}\text { Fragmentos } \\
\text { polimórficos }\end{array}$ \\
\hline OPB1 & 9 & 8 \\
\hline OPB2 & 10 & 10 \\
\hline OPB3 & 11 & 11 \\
\hline OPB4 & 12 & 12 \\
\hline OPB5 & 13 & 12 \\
\hline OPB6 & 16 & 14 \\
\hline OPB7 & 15 & 14 \\
\hline OPB8 & 15 & 14 \\
\hline OPB9 & 14 & 13 \\
\hline OPB10 & 12 & 12 \\
\hline OPB11 & 12 & 11 \\
\hline OPB12 & 11 & 11 \\
\hline OPB13 & 10 & 10 \\
\hline OPB14 & 11 & 11 \\
\hline OPB16 & 7 & 7 \\
\hline
\end{tabular}


265 bandas diferentes foram obtidas, sendo que $256(96 \%)$ apresentaram polimorfismo (Tabela 2).

Pelo polimorfismo observado pelas reações de amplificação utilizando os "primers" B11 e A11 (Fig. 9), verifica-se o elevado nível de polimorfismo, tanto em nível intra como interespecífico e, ainda maior, intergêneros. As duas combinações híbridas de açaí e juçara, AS e GE, apresentaram perfis diferentes de bandas com alguns "primers" como o B11, revelando que os progenitores são heterozigotos, mas não com outros, como o A11. Por outro lado, ambos, além de outros seis (A3, A8, A12, B2 e B12), permitiram reconhecer o híbrido entre E. oleracea e E. edulis, enquanto "primers", como o B6 (Fig. 9), apenas diferenciaram os híbridos entre si. A utilização destes marcadores para identificação precoce de híbridos interespecíficos dentro do gênero Euterpe pode significar uma importante ferramenta de auxílio ao melhorista.

\section{Análise multivariada}

O dendrograma observado na Fig. 10 (UPGMA), com coeficiente cofonético 0,97, apresenta a classificação dos ecótipos deste estudo em função dos dados fornecidos pelas isoenzimas. A Fig. 10 foi obtida a partir do coeficiente de similaridade genética entre os diferentes genótipos, sendo que oitenta e quatro bandas polimórficas foram tomadas para o cálculo deste coeficiente. Observase, na Fig. 10, o forte agrupamento dos ecótipos de pupunha (Bactris gasipaes), assim como das espécies e ecótipos de Euterpe. Neste gênero, o híbrido interespecífico entre $E$. oleracea e $E$. edulis apresentou-se mais próximo de E.oleracea, espécie utilizada como progenitor feminino. Observações de campo realizadas nos híbridos entre estas duas espécies revelam a existência de características agronômicas importantes adquiridas do genótipo materno, como é o caso do perfilha-

A11

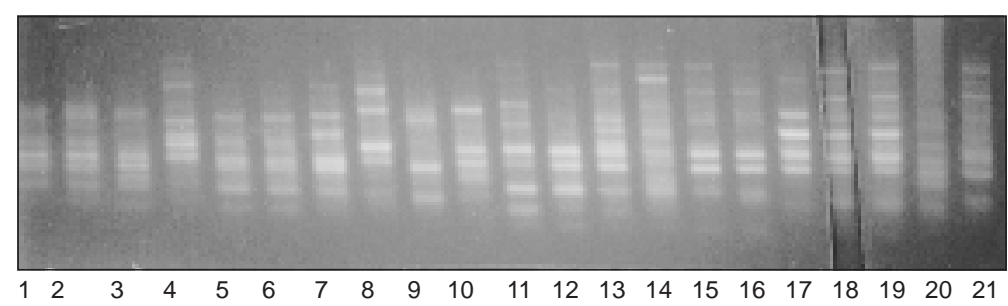

B11
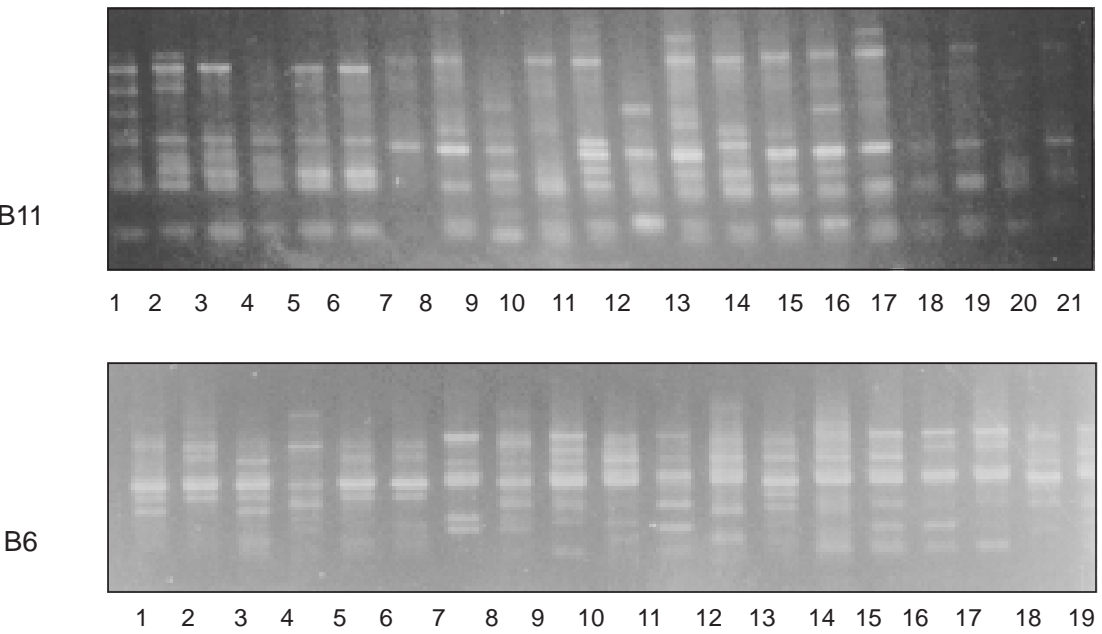

Fig. 9 - Perfil RAPD para os "primers" A11, B11 e B6 em palmeiras. 1 = yurimaguas; 2 = benjamim constant; $3=$ branca una; $4=\mathrm{t} 2 \mathrm{~s} 1 ; 5=6=$ E.E.U. sem e com espinho; $7=$ dendê hermes; $8=$ euterpe tadeu; $9=$ gariroba; $10=11=12=13=14=$ açaís itajobi, açaí, espada, pariquera, danilo; $15=16=$ híbridos AS e GE; $17=18=19=$ juçaras GE, T, AS; $20=$ ceplac $10 ; 21=$ bahia. 
mento, o que pode ser indicativo de um sistema de herança citoplasmática. Bovi (1984) e Bovi et al. (1987) já tinham aventado essa possibilidade, quando analisaram a porcentagem de plantas perfilhadas e o número de perfilhos por touceira de plantas originárias do cruzamento normal $(E$. oleracea $\mathrm{x}$ E. edulis) e do cruzamento recíproco (E. edulis x E. oleracea). A obtenção de marcadores associados às características agronômicas de interesse, como é o caso do perfilhamento, é bastante desejável em programas de melhoramento genético, uma vez que tais características poderiam ser direcionadas e/ou observadas ao longo dos ciclos de seleção através destes marcadores. A identificação precoce feita por meio de marcadores relacionados, principalmente, aos componentes da produção, entre os quais o perfilhamento se inclui (Bovi et al., 1988), é de importância capital em se tratando de espécies perenes, de ciclo longo, como as palmeiras.

No entanto, deve ser mencionado que os resultados obtidos neste estudo dizem respeito apenas ao cruzamento entre E. oleracea e E. edulis. Estudos mais detalhados, envolvendo cruzamentos

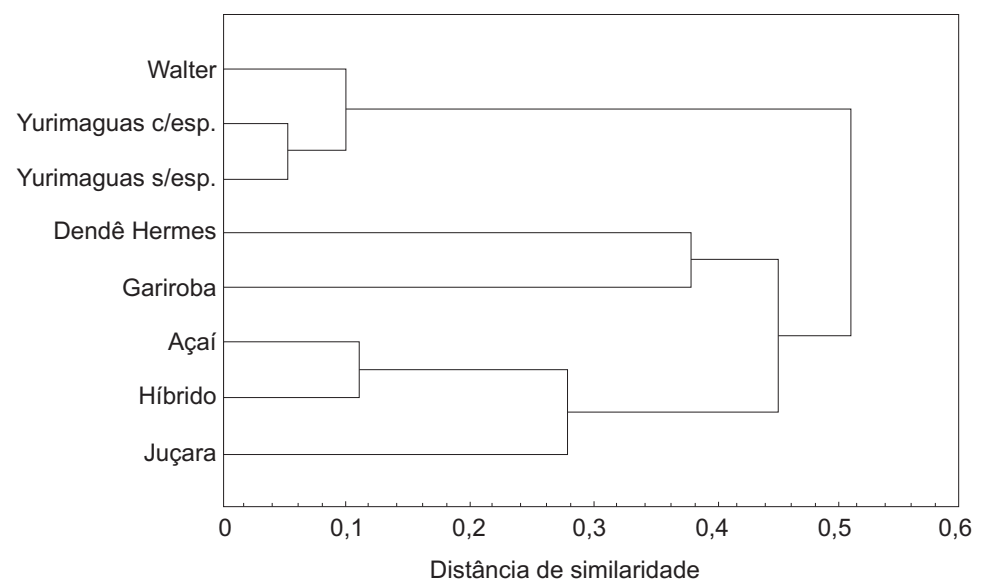

Fig. 10 - Dendrograma UPGMA para representação de 8 genótipos de palmeiras em função das similaridades genéticas entre elas, calculadas a partir de 84 bandas polimórficas de isoenzimas.

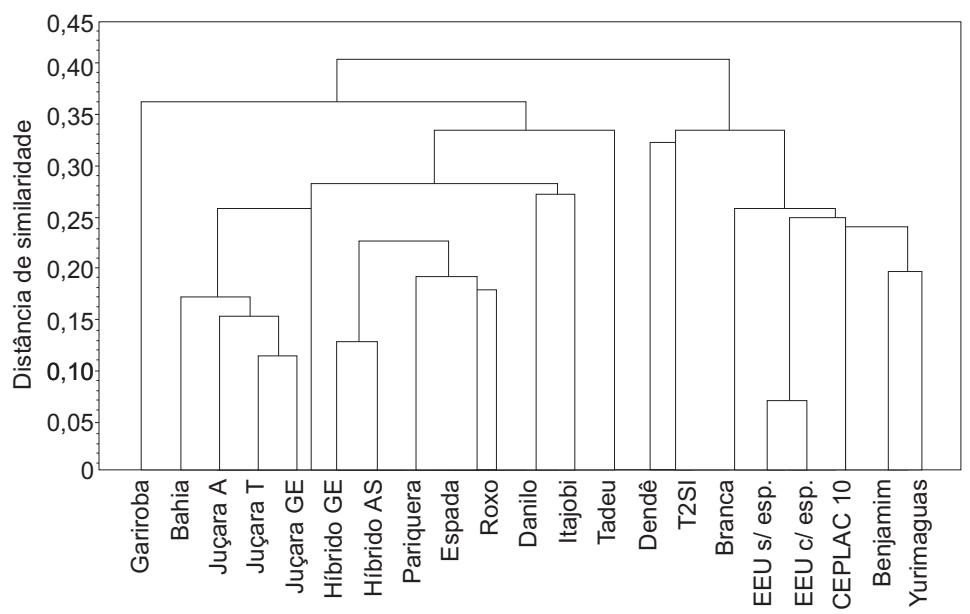

Fig. 11 - Dendrograma UPGMA para representação de 21 genótipos de palmeiras em função das similaridades genéticas entre elas, calculadas a partir de 256 bandas RAPDs. 
com outras espécies do gênero e com um maior número de descendentes são necessários.

A classificação hierárquica das palmeiras em função dos dados RAPD está representada na Fig. 11. Da mesma forma que para as isoenzimas, o dendrograma observado, com coeficiente cofonético 0,92 , foi obtido a partir do coeficiente de similaridade genética entre os genótipos, calculado em função das 256 bandas polimórficas consideradas para análise.

Observa-se nesta figura que os ecótipos de pupunheiras classificados como EEU, com e sem espinhos, apresentam-se fortemente ligados, seguidos por ordem de afinidade genética dos ecótipos de pupunha de Benjamin Constant, Yurimaguas, Itabuna, Iquitos e Pará (Mococa). Em relação aos gêneros mais distantes das palmeiras mais utilizadas para palmito (Euterpe e Bactris), a espécie Elaeis guineensis posicionou-se mais próxima das pupunhas, enquanto que Syagrus oleracea aproximou-se mais das palmeiras do gênero Euterpe, especialmente àquelas sem perfilhamento.

Em relação ao gênero Euterpe houve agrupamento das espécies e ecótipos avaliados neste estudo. Os ecótipos com perfilhamento apresentaram maior proximidade genética entre si, distanciando-se dos sem perfilhamento. Os híbridos ocuparam posições intermediárias entre os dois grupos formados (com e sem perfilhamento). Interessante notar o agrupamento entre o açaí de Itajobi e o açaí Pancas, ambos da mesma região geográfica, e o distanciamento deles com os ecótipos do Pará. A espécie E. caatinga, ocorrendo naturalmente na forma perfilhada e nãoperfilhada (Judas Tadeu de Medeiros Costa, comunicação pessoal), separa-se bastante das demais espécies, apresentando, porém, maior proximidade com os açaizeiros de Minas Gerais e Espírito Santo. O ecótipo açaí espada muito distinto morfologicamente do açaí roxo 1, apresenta, no entanto, grande afinidade genética com este, ambos um pouco distantes geneticamente do ecótipo de açaí, também roxo (roxo 2), mas de outra origem geográfica. Os ecótipos da espécie Euterpe edulis, os três do Vale do Ribeira, SP, mostraram-se bastante próximos entre si, confirmando a importância da origem geográfica. Pelo dendrograma apresentado na Fig. 11, nota-se que a espécie E. espiritossantensis, nativa no Espírito Santo e sul da Bahia, possui grande afinidade genética com a E. edulis, de ocorrência natural na região sudeste brasileira.
Embora morfologicamente distinta, especialmente nos elementos e eventos florais (Bovi et al., 1994), é do tipo monocaule, da mesma forma como os ecótipos de E. edulis. Corroborando resultados de isoenzimas, observou-se também que os híbridos interespecíficos entre E. oleracea e E. edulis apresentaram maior afinidade genética com os ecótipos de E. oleracea, espécie utilizada como progenitor feminino.

De uma maneira geral, verificou-se que o dendrograma das isoenzimas foi semelhante ao obtido pelos marcadores RAPD, indicando que as bandas observadas foram produtos de expressão gênica.

\section{CONCLUSÕES}

O polimorfismo enzimático e de RAPDs observado em palmeiras possibilitou a diferenciação entre gêneros, espécies, ecótipos e híbridos existentes nos BAGs.

Pelos zimogramas das palmeiras foram observadas várias bandas não relatadas por trabalhos anteriores. O sistema PGI apresentou-se de acordo com a literatura como dimérico e codificado por dois locos, tendo sido observadas de uma a três bandas em duas regiões com nove diferentes velocidades de migração. Este sistema algumas vezes caracterizou o híbrido entre Euterpe oleracea e E. edulis. O GOT apresentou-se, de acordo com a literatura, como dimérico e codificado por dois locos, tendo sido observadas de uma a três bandas em duas regiões com nove velocidades de migração. No LAP foram observadas de uma a duas bandas com sete diferentes migrações. No APS foram observadas duas regiões de bandas com cinco velocidades de migração, tendo pelo menos um sistema o fenótipo dimérico característico. O PGM apresentou-se, de acordo com a literatura, como monomérico, sendo observada uma região com uma a duas bandas com seis diferentes migrações. Os sistemas EST e PRX apresentaram várias bandas em duas regiões, sendo que uma banda da PRX caracterizou o híbrido entre Euterpe oleracea e E. edulis, por se apresentar sempre em uma posição intermediária entre elas. Pelo sistema MDH observou-se a ocorrência de heterozigose entre pupunhas.

Os dendrogramas produzidos pelas bandas das isoenzimas e marcadores RAPD foram bastante semelhantes em palmeiras, sugerindo que as bandas observadas foram produtos de expressão gênica. 
A diversidade das ligações, tanto entre ecótipos de Bactris gasipaes, quanto a espécies e ecótipos de palmeiras do gênero Euterpe comprovou a existência de variabilidade genética dentro desses dois gêneros. Por outro lado, mostrou haver uma similaridade entre ecótipos e/ou espécies de acordo com a região geográfica de ocorrência natural. As pupunhas formaram um agrupamento distinto ligando-se as EEU com e sem espinho a benjamim constant, yurimaguas, ceplac 10, branca una e por último a T2S1. Pelo agrupamento das euterpes, verificou-se a estreita ligação entre as juçaras, a posição intermediária dos híbridos entre as juçaras e açaís comuns, espada e pariquera e a seguir a ligação com as açaís danilo, itajobi e finalmente a euterpe tadeu. A diversidade das ligações entre os diferentes ecótipos da açaí comprovou a existência de variabilidade genética. A gariroba (Syagrus oleraceae) ficou mais ligada às euterpes, enquanto a dendê hermes (Elaeis guineensis), às pupunhas. Pelas informações a respeito da variabilidade genética disponível, este estudo deverá facilitar o trabalho dos melhoristas. Além da caracterização, a adequação de metodologias, como a de eletroforese de isoenzimas em géis de poliacrilamida e a de marcadores RAPD, contribui para os programas de melhoramento pelo aumento dos dados existentes acerca da variabilidade genética.

\section{REFERÊNCIAS BIBLIOGRÁFICAS}

ALFENAS, A. C., PETERS, I., WALTER, B. \& PAS SADOR, C. G., 1991, Eletroforese de proteínas e isoenzimas de fungos e essências florestais. Viçosa, Universidade Federal de Viçosa, Minas Gerais, 242p.

BALLVÉ, R. M. L., 1988, Isoenzimas como marcadores genéticos em palmiteiro (Euterpe spp). Campinas, 116p. Tese de Mestrado em Biologia, IB-UNICAMP, 95p.

BOVI, M. L. A. \& CARDOSO, M., 1978, Pesquisas com o palmiteiro (Euterpe edulis Mart.). Campinas, Instituto Agronômico, 46p.

BOVI, M. L. A., 1984, Pesquisas em desenvolvimento com o açaizeiro no Instituto Agronômico. O Agronômico, Campinas, 36(2): 155-178.

BOVI, M. L. A., GODOY JÚNIOR, J. \& SÁES, L. A., 1987, Híbridos interespecíficos de palmiteiro (Euterpe oleracea X E. edulis). Bragantia, 46(2): 343-363.

BOVI, M. L. A., GODOY Jr., G., \& SAES, L. A., 1988, Pesquisas com os gêneros Euterpe e Bactris no Instituto Agronômico de Campinas. In: ENCONTRO NACIONAL DE PESQUISADORES EM PALMITO, Curitiba, Anais. Brasília, EMBRAPA-CNPF, 295p.
BOVI, M. L. A., GODOY Jr., G., SPIERING, S. H. \& CAMARGO, S. B., 1990, Relação entre alguns caracteres da planta e do palmito de açaizeiros (Euterpe oleracea). Bragantia, 49(1): 69-81.

BOVI, M. L. A., GODOY Jr. G. \& SAES, L. A., 1991, Correlações fenotípicas entre caracteres da palmeira Euterpe edulis Mart. e produção de palmito. Rev. Brasil. Gen. 14(1): 105121.

BOVI, M. L. A., GODOY Jr., G., SPIERING, S. H. \& CAMARGO, S. B., 1993, Seleção precoce em pupunheiras (Bactris gasipaes H. B. K.) para produção de palmito. In: Congresso Internacional sobre Biologia, Agronomia e Industrialización del pijuayo, 4, Iquitos, Anais. San José, U.F.C.R., p. 177-195

BOVI, M. L. A., VAL, M. R., DIAS, G. S. \& SPIERING, S. H., 1994, Floral biology and reproductive system of Euterpe espiritosantensis Fernandes. Acta Horticulturae, 360: 41-56.

BOVI, M. L. A, SPIERING, S. H., SÁES, L. A. \& GODOY, Jr., G., 1995a, Coleta e Caracterização morfológica de germoplasma de Euterpe. Simpósio Nacional de Recursos Genéticos Vegetais, Campinas, 1995a. Resumos, p. 34.

BOVI, M. L. A., GERMEK, E. B., GALlO, P. B., SÁES, L. A., GODOY Jr., G., MARTINS, A. L. M., PAUlO, E. M., KANTHACK, R. A. D., MARTINS, F. P., SANTOS, R. R., BORTOLETTO, N., CAMPANA, M. P. \& CAMARGO, A. P., 1995b, Conservação e caracterização de germoplasma de pupunheira (Bactris gasipaes) em uso no Instituto Agronômico. Simpósio Nacional de Recursos Genéticos Vegetais, Campinas. Resumos, p. 66.

GUESQUIÉRE, M., 1983, Contribuition a l'etude de la variabilite genétique du palmier a huile (Elaeis guineensis): le polymorphisme enzymatique. Paris, Doctoral Thesis, Universite de Paris, Sud Centre D'Orsay.

JACCARD, P., 1908, Nouvelles recherches sur la distribuition florale. Bull. Soc. Vaud. Sci. Nat., 44: 223-270.

MURRAY, M. G. \& THOMPSON, W. F., 1980, Rapid isolation of high molecular weight plant DNA. Nucl. Acids Res. 8: 4321-4326.

ROLHF, J. F., 1993, Numerical taxonomy and multivariate analysis system. New York, Exeter Software. Version 1.70.

SAWAZAKI, H. E., 1995, Caracterização da diversidade genética em plantas cítricas, palmeiras e brássicas através de isoenzimas e RAPD. Campinas, 1995, 116p. Tese de Doutorado em Biologia, IB-UNICAMP.

SHAH, F. H., RASHID, O., SIMONS, A. J. \& DUNSDON, A., 1994, The utility of RAPD markers for the determination of genetic variation in oil palm (Elaeis guineensis). Theor. Appl. Genet., 89: 713-718.

TANKSLEY, S. D. \& ORTON, T. J., (eds.), 1983, Isozumos in plant genetics and breeding. Elsevier Science Publishers, Amsterdan.

TORRES, A. M. \& TISSERAT, B., 1980, Leaf Isozymes as genetic markers in date palms. Amer. J. Bot., 67: 162-167.

WEEDEN, N. F. \& WENDEL, J. F., 1989, Isozymes and Plant Biology: Genetics of plant isozymes (ed. by Soltis \& Soltis), Portland, Dioscorides Press, pp. 46-73. 